\title{
A phase II open label, randomised study of ipilimumab with temozolomide versus temozolomide alone after surgery and chemoradiotherapy in patients with recently diagnosed glioblastoma: the Ipi- Glio trial protocol
}

\author{
Nicholas F. Brown ${ }^{1}$, Stasya M. Ng${ }^{2}$, Claire Brooks², Tim Coutts², Jane Holmes ${ }^{3}$, Corran Roberts ${ }^{3}$, Leena Elhussein ${ }^{3}$, \\ Peter Hoskin ${ }^{4}$, Tim Maughan ${ }^{5}$, Sarah Blagden ${ }^{6}$ and Paul Mulholland ${ }^{1,4,7^{*}}$ (i)
}

\begin{abstract}
Background: Median survival for patients with glioblastoma is less than a year. Standard treatment consists of surgical debulking if feasible followed by temozolomide chemo-radiotherapy. The immune checkpoint inhibitor ipilimumab targets cytotoxic T-lymphocyte-associated protein 4 (CTLA-4) and has shown clinical efficacy in preclinical models of glioblastoma. The aim of this study is to explore the addition of ipilimumab to standard therapy in patients with glioblastoma.
\end{abstract}

Methods/design: Ipi-Glio is a phase II, open label, randomised study of ipilimumab with temozolomide (Arm A) versus temozolomide alone (Arm B) after surgery and chemoradiotherapy in patients with recently diagnosed glioblastoma. Planned accrual is 120 patients (Arm A: 80, Arm B: 40). Endpoints include overall survival, 18-month survival, 5-year survival, and adverse events. The trial is currently recruiting in seven centres in the United Kingdom.

Trial registration: ISRCTN84434175. Registered 12 November 2018.

Keywords: Glioblastoma, Glioma, Ipilimumab, Temozolomide

\section{Background}

Glioblastoma is the most common malignant primary brain tumour [1]. Survival is poor, with a median survival from diagnosis of 14.6-21.1 months with standard therapy in clinical trials [2-7]. However, registry databases report overall survival of only $6-10$ months $[8,9]$. Standard therapy is surgical debulking if feasible, with the degree of resection correlating with prognosis [1013]. This is followed by adjuvant chemoradiotherapy

\footnotetext{
*Correspondence: paul.mulholland@nhs.net

${ }^{1}$ Department of Oncology, University College London Hospitals, 250 Euston Road, London NW1 2PQ, UK

${ }^{4}$ Mount Vernon Cancer Centre, Rickmansworth Road, Northwood HA6 2RN, UK

Full list of author information is available at the end of the article
}

given within 6 weeks of surgery, with 60 Gray (Gy) of fractionated focal external beam radiotherapy administered in 30 fractions over 6 weeks, along with daily concomitant temozolomide $75 \mathrm{mg} / \mathrm{m}^{2}$. Following a 28-day break, patients receive six cycles of adjuvant temozolomide $150-200 \mathrm{mg} / \mathrm{m}^{2}$, given for 5 days in a 28 -day cycle. This standard was implemented following demonstration of a 2.5 month median survival benefit over radiotherapy alone in the landmark EORTC-NCIC randomised phase III trial $[6,14]$. There is no standard therapy for patients at relapse who are typically treated with lomustine given as monotherapy or in combination with procarbazine and vincristine $(\mathrm{PCV})[15,16]$.

The traditional dogma of the CNS as an immuneprivileged site has been widely eroded, and there is now 
convincing evidence that the CNS has a fully functioning, although tightly regulated, innate and adaptive immune system, underpinned by a functional lymphatic system [17]. Malignant gliomas elicit systemic immune dysregulation, with reduced CD4+ T-cell number and function, and increased Tregs [18-21].

The amplitude and quality of T-cell responses are regulated by a balance of co-inhibitory and co-stimulatory signals, termed immune checkpoints. These "checkpoints" allow a rapid and effective response against foreign antigens, whilst preventing overstimulation and auto-immune responses. T-cell activation after antigen recognition by the $\mathrm{T}$-cell receptor is a complex integration of these stimulatory and inhibitory signals. Gliomas exploit these checkpoints, with expression of negative regulators of immune response and conversion of cytotoxic T-cells to regulatory $\mathrm{T}$-cells in the tumour microenvironment to escape immune surveillance $[17,22]$.

Cytotoxic T-lymphocyte antigen-4 (CTLA-4, CD152) is a CD28 homolog with a 100-1000 higher affinity for B7 (CD80/86). However, unlike CD28, CTLA-4 does not produce a costimulatory signal when bound to $\mathrm{B} 7$. The degree of CD28:B7 binding versus CTLA-4:B7 binding determines whether a $\mathrm{T}$ cell is activated or undergoes anergy [23]. In resting naïve T cells CTLA-4 is regulated in part by its subcellular localisation: it is principally found in intracellular vesicles and not functional until expressed on the cell surface [24]. CTLA-4 is constitutively expressed on Tregs and plays a key role in generating tolerance [25]. Thus CTLA-4 is a principal regulator of an effective immune response [26-28].

Ipilimumab is a human IgG monoclonal antibody specific for CTLA-4 and blocks the interaction with B7, augmenting $\mathrm{T}$ cell activation and proliferation. In preclinical glioblastoma models, systemic CTLA-4 blockade produces an effective $\mathrm{T}$-cell response, tumour shrinkage, and prolongs survival [29-32]. Efficacy in patients with melanoma with brain metastases provide clinical evidence of activity within the central nervous system [33-35].

The aim of this phase II trial is to evaluate the addition of ipilimumab to standard therapy in patients with recently diagnosed glioblastoma. This manuscript describes protocol version 3.0 (13 August 2019).

\section{Methods}

\section{Study objectives}

The primary objective of this study is to evaluate whether the addition of ipilimumab to the current standard of care following surgery and radiotherapy will improve survival in patients with newly diagnosed glioblastoma. Secondary objectives are evaluation of the safety and tolerability of ipilimumab with temozolomide versus temozolomide alone, and whether the addition of ipilimumab to the standard of care improves long term survival. Accordingly, the study endpoints are overall survival, overall survival at 18 months, overall survival at 5 years, and any toxicity grade 3 of higher according to the Common Terminology Criteria for Adverse Events (CTCAE) v4.03 [36].

\section{Trial design}

This study is an open label, stratified randomised, multicentre, phase II clinical trial. Following informed consent, patients will enter a screening phase during which the eligibility for randomisation will be determined. $\mathrm{Pa}$ tients who meet the eligibility criteria will be randomly allocated in a 2:1 ratio to receive either ipilimumab with temozolomide (Arm A) or temozolomide alone (Arm B). A total of 120 patients will be randomised, with 80 patients in Arm A and 40 patients in Arm B. Treatment allocation will be by minimisation incorporating a random element, and will be carried out by computer. Randomisation will be stratified by extent of surgery (total versus subtotal resection) and MGMT promotor methylation (methylated, unmethylated, or unknown). Randomised patients will enter the treatment phase. After stopping study treatment, patients will remain on study for surveillance for 52 weeks following the date of randomisation. Tumour progression will be assessed by contrast enhanced MRI performed every 12 weeks as per standard care until tumour progression. Survival status will be collected at 18 months from the date the last patient is randomised, and at 2, 3 and 5 years from each patient's randomisation date.

\section{Patient cohort}

Patients are currently being recruited from 7 sites in the United Kingdom (Addenbrooke's Hospital, Cambridge; Churchill Hospital, Oxford; Guy's Hospital, London; Mount Vernon Cancer Centre, Middlesex; The Christie, Manchester; University College Hospital, London; Western General Hospital, Edinburgh). The first patient enrolled in January 2019.

Inclusion criteria include: newly diagnosed histologically confirmed de-novo supratentorial glioblastoma with greater than $20 \%$ surgical debulking; radiotherapy to have begun within 49 days of surgery; completed standard radiotherapy with concurrent oral temozolomide; age 18-70 years of age; life expectancy of at least 12 weeks; ECOG performance status 0 or 1 ; haemoglobin $\geq 9 \mathrm{~g} / \mathrm{dL}$; platelet count $\geq 100 \times 10^{9} / \mathrm{L}$; absolute neutrophil count (ANC) $\geq 1 \times 10^{9} / \mathrm{L}$; lymphocyte count $\geq 0.5 \times 10^{9} / \mathrm{L}$; serum creatinine $<1.5$ upper limit of normal (ULN) or Cockroft-Gault creatinine clearance $\geq 50$ $\mathrm{mL} / \mathrm{min}$; bilirubin $\leq 1.5 \mathrm{x}$ ULN (or $\leq 3 \mathrm{x}$ if known Gilbert's syndrome); ALT or AST $\leq 3 x$ ULN. 
Exclusion criteria include: multifocal glioblastoma; secondary glioblastoma; known extracranial or leptomeningeal disease; any other treatment for glioblastoma other than surgery and temozolomide chemoradiotherapy; dexamethasone dose $>3 \mathrm{mg}$ daily (or equivalent); significant intra- or peri-tumoral haemorrhage; clinically relevant, active, known or suspected autoimmune disease; history of significant gastrointestinal impairment; history of interstitial lung disease; any condition requiring systemic steroid therapy ( $>10 \mathrm{mg}$ prednisolone daily or equivalent); other active malignancy; known history of Hepatitis B or C or HIV; and pregnant or breast-feeding women.

\section{Study treatment}

Study treatments include ipilimumab $\left(\right.$ Yervoy $\left.^{\mathrm{mm}}\right)$ (Arm A) and temozolomide (TMZ) (Arms A and B).

\section{Ipilimumab}

Ipilimumab will be dosed at $3 \mathrm{mg} / \mathrm{kg}$ and administered as an intravenous infusion over $90 \mathrm{~min}$. The first cycle of ipilimumab will be administered within 14 days of completing radiotherapy and within 3 days of randomisation. Ipilimumab will be administered once every 3 weeks for a total of 4 infusions. No dose reduction is permitted.

Dosing will be delayed in the following occurrences: grade $\geq 2$ adverse events (AEs) (except grade 2 skin AEs, fatigue, or laboratory abnormalities other than ALT/ AST); grade 3 skin AEs; grade 3 laboratory AEs (except grade $\geq 3$ lymphopaenia or grade $\geq 3$ amylase/lipase if no clinical evidence of pancreatitis). Ipilimumab retreatment may resume once the $\mathrm{AE}$ returns to grade $\leq 1$ or baseline. Patients may resume treatment with grade 2 fatigue, or drug-related endocrinopathies once adequately controlled with physiological hormone replacement if discussed and approved by the trial management group. Ipilimumab related pulmonary AEs, diarrhoea or colitis must return to baseline prior to resuming treatments except grade $\geq 3$ diarrhoea/colitis where ipilimumab must be permanently discontinued. Persistent grade 1 pneumonitis may resume treatment after a steroid taper over at least 1 month.

Ipilimumab will be permanently discontinued if any of the following suspected ipilimumab related AEs occur: grade $\geq 2$ uveitis, eye pain, or blurred vision that does not respond to topical therapy and does not improve to grade 1 severity within the retreatment period, or that requires systemic treatment; grade $\geq 3$ uveitis, pneumonitis, bronchospasm, hypersensitivity reaction, or infusion reaction; grade $\geq 3$ drug-related AEs, with the following exceptions: grade 3 skin AEs, endocrinopathies adequately controlled with only physiological hormonal replacement, and laboratory abnormalities (other than the following which do require discontinuation: grade 3 thrombocytopenia or associated with bleeding, AST or ALT $>5-10 \times$ ULN for $>14$ days, AST or ALT $>10 x$ ULN, total bilirubin $>5 \times$ ULN, concurrent AST or ALT $>3 \times$ ULN and total bilirubin $>2 \times$ ULN); any grade 4 $\mathrm{AE}$ except skin AEs only where not considered to be related to ipilimumab, neutropenia, lymphopenia or leukopenia, isolated lipase/amylase elevations without clinical manifestations of pancreatitis and endocrinopathies which resolve or are adequately controlled with physiological hormone replacement (as discussed with trial management group); or dosing delays $>42$ days from the previous dose (unless approved by the trial management group).

\section{Temozolomide}

Temozolomide will be administered orally for 6 cycles in both Arms A \& B. Temozolomide will commence as per standard care following completion of chemoradiotherapy. Dosing is once daily for 5 days in a 28 -day cycle. The dose in cycle 1 is $150 \mathrm{mg} / \mathrm{m}^{2}$ (dose level 0), unless ANC $<1.5 \times 10^{9} / \mathrm{L}$, platelet count $<100 \times 10^{9} / \mathrm{L}$, or any non-haematological toxicity $\geq$ grade 2 (except alopecia, nausea, vomiting) during concomitant temozolomide administration with radiotherapy, in which case temozolomide will be initiated at $100 \mathrm{mg} / \mathrm{m}^{2}$ (dose level - 1). If no non-haematological toxicity $\geq$ grade 2 (except alopecia, nausea, or vomiting) is experienced in cycle 1 , ANC is $\geq 1.5 \times 10^{9} / \mathrm{L}$, and platelet count $\geq 100 \times 10^{9} / \mathrm{L}$ the dose is escalated to $200 \mathrm{mg} / \mathrm{m}^{2}$ (dose level 1) from cycle 2 (or to $150 \mathrm{mg} / \mathrm{m}^{2}$ if cycle 1 was dosed at $100 \mathrm{mg} / \mathrm{m}^{2}$ ). If the dose was not escalated at Cycle 2, escalation is not done in subsequent cycles. The temozolomide dose will be reduced if ANC $<1.0 \times 10^{9} / \mathrm{L}$ or platelet count $<75 \times 10^{9} /$ L or for grade 3 non-haematological toxicity (except alopecia, nausea, vomiting). If AEs persist, treatment will be delayed by 1 week for up to 4 consecutive weeks, after which if AEs have not resolved to $\leq$ grade 1 then temozolomide will be discontinued. Temozolomide will be stopped if the same grade 3 non-haematological toxicity (except alopecia, nausea, vomiting) recurs after dose reduction, or if treatment at dose level-1 results in unacceptable toxicity.

\section{Statistical considerations}

To give a power of $80 \%$ to show a significant difference of 22.5 month median survival in Arm A (ipilimumab + temozolomide) and 15 month median survival in Arm B (temozolomide alone) at one sided $20 \%$, allowing for $5 \%$ loss to follow-up at 3 years, 120 patients need to be recruited (80 to Arm A, 40 to Arm B). This assumes an 18-month recruitment period and survival follow-up for a minimum of 18 months. 


\section{Discussion}

The objective of this study is to evaluate whether the addition of ipilimumab to temozolomide following standard chemoradiotherapy improves survival in patient with glioblastoma. Given the recent failures of phase 3 trials of new therapies in glioblastoma to demonstrate survival benefit following apparent efficacy in single arm phase II trials [37], Ipi-Glio includes a standard of care $\operatorname{arm}$ (Arm B), with a 2:1 randomisation between Arm A and $B$ in order to aid recruitment.

A limitation of this study is a lack of biomarkers to provide potential determinants of clinical response to ipilimumab. There is no accepted biomarker for response to ipilimumab therapy. Studies in melanoma have found a number of markers that are associated with response to ipilimumab, including expression of genes associated with antigen presentation [38], the T-cell receptor repertoire [39], HLA-I heterozygosity [40], tumour mutational burden [39], somatic copy number mutation burden [41]; systemic immune response factors such as serum IL-6 levels [42]; and gut microbiome variants [43]. These factors will need to be considered in future studies. Further, antibiotic use in the month prior to administration of the PD-1 checkpoint inhibitor nivolumab is associated with poorer survival [44]. This is of particular importance for glioblastoma, as cotrimoxazole is routinely administered with temozolomide chemoradiotherapy as prophylaxis against P.jiroveci pneumonia. In Ipi-Glio, patients are enrolled after completing radiotherapy, but in future trials withdrawal of routine co-trimoxazole should be considered. The IpiGlio study is currently ongoing.

\section{Abbreviations \\ AE: Adverse event; ANC: Absolute neutrophil count; CNS: Central nervous system; CTCAE: Common Terminology Criteria for Adverse Events; CTLA- 4: Cytotoxic T-lymphocyte-associated protein 4; Gy: Gray; PCV: Procarbazine, lomustine, vincristine; RT: Radiotherapy; TMZ: Temozolomide; ULN: Upper limit of normal}

\section{Acknowledgements}

We are thankful to staff at participating hospitals, patients, and their families and carers for their contributions to the study. The study sites receive infrastructure support from National Institute for Health Research (NIHR) Biomedical Research Centre (BRC) initiatives. The trial is sponsored by the University of Oxford and managed by the Oncology Clinical Trials Office (OCTO). Independent oversight of the trial is provided by the Radiotherapy and Imaging Trial Oversight Committee (RIOC).

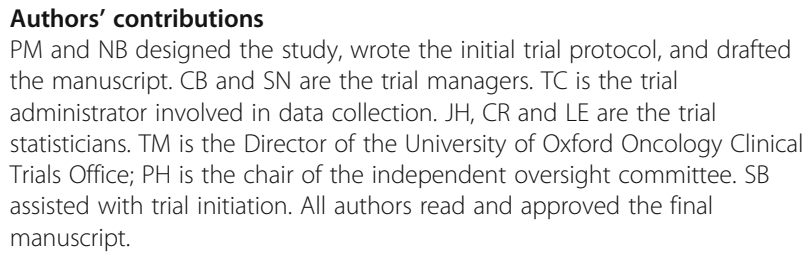

\section{Funding}

Ipi-Glio is funded by the National Brain Appeal and Bristol-Myers Squibb with further funding support from the CRUK Oxford Centre. The National Brain
Appeal and Bristol-Myers Squibb had no role in the design of the study or collection, analysis, and interpretation of data, or in the writing of this manuscript. The manuscript was reviewed by the funding bodies prior to publication.

\section{Availability of data and materials \\ Not applicable.}

\section{Ethics approval and consent to participate}

This study will be conducted in accordance with the Declaration of Helsinki, the principles of Good Clinical Practice, and applicable clinical trials regulations. Study conduct is approved by the South Central (Oxford B) Research Ethics Committee (18/SC/0525) and the Medicines and Healthcare Regulatory Agency. All patients will provide written informed consent prior to participation in the trial. The clinical sites are Addenbrooke's Hospital (Cambridge University Hospitals NHS Foundation Trust), The Christie (The Christie NHS Foundation Trust), Churchill Hospital (Oxford University Hospitals NHS Foundation Trust), Guy's Hospital (Guy's and St Thomas' NHS Foundation Trust), Mount Vernon Cancer Centre (The Hillingdon Hospitals NHS Foundation Trust), University College Hospital (University College London Hospitals NHS Foundation Trust), and Western General Hospital (NHS Lothian).

\section{Consent for publication}

Not applicable.

\section{Competing interests}

The authors declare that they have no competing interests.

\section{Author details}

'Department of Oncology, University College London Hospitals, 250 Euston Road, London NW1 2PQ, UK. ${ }^{2}$ Oncology Clinical Trials Office (OCTO), Department of Oncology, The University of Oxford, Old Road Campus Research Building, Oxford OX3 7DQ, UK. ${ }^{3}$ Centre for Statistics in Medicine (CSM), University of Oxford, Botnar Research Centre, Windmill Road, Oxford OX3 7LD, UK. ${ }^{4}$ Mount Vernon Cancer Centre, Rickmansworth Road, Northwood HA6 2RN, UK. ${ }^{5}$ Oxford Institute for Radiation Oncology, University of Oxford, Old Road Campus Research Building, Roosevelt Drive, Oxford OX3 7DQ, UK. ${ }^{6}$ Department of Oncology, University of Oxford, Old Road Campus Research Building, Oxford OX3 7DQ, UK. ${ }^{7}$ UCL Cancer Institute, 72 Huntley St, London WC1E 6AG, UK.

Received: 19 November 2019 Accepted: 11 February 2020

Published online: 12 March 2020

\section{References}

1. Louis DN, Perry A, Reifenberger G, von Deimling A, Figarella-Branger D, Cavenee WK, Ohgaki H, Wiestler OD, Kleihues P, Ellison DW. The 2016 World Health Organization classification of tumors of the central nervous system: a summary. Acta Neuropathol. 2016;131(6):803-20.

2. Chinot OL, Wick W, Mason W, Henriksson R, Saran F, Nishikawa R, Carpentier AF, Hoang-Xuan K, Kavan P, Cernea D, et al. Bevacizumab plus radiotherapytemozolomide for newly diagnosed glioblastoma. N Engl J Med. 2014; 370(8):709-22.

3. Gilbert MR, Dignam JJ, Armstrong TS, Wefel JS, Blumenthal DT, Vogelbaum MA, Colman H, Chakravarti A, Pugh S, Won M, et al. A randomized trial of bevacizumab for newly diagnosed glioblastoma. N Engl J Med. 2014;370(8): 699-708.

4. Johnson DR, O'Neill BP. Glioblastoma survival in the United States before and during the temozolomide era. J Neurooncol. 2012;107(2):359-64.

5. Malkki H. Trial watch: Glioblastoma vaccine therapy disappointment in phase III trial. Nat Rev Neurol. 2016;12(4):190.

6. Stupp R, Hegi ME, Mason WP, van den Bent MJ, Taphoorn MJ, Janzer RC, Ludwin SK, Allgeier A, Fisher B, Belanger K, et al. Effects of radiotherapy with concomitant and adjuvant temozolomide versus radiotherapy alone on survival in glioblastoma in a randomised phase III study: 5-year analysis of the EORTC-NCIC trial. Lancet Oncol. 2009;10(5):459-66.

7. Stupp R, Taillibert S, Kanner AA, et al. Maintenance therapy with tumortreating fields plus temozolomide vs temozolomide alone for glioblastoma: a randomized clinical trial. JAMA. 2015;314(23):2535-43. 
8. Brodbelt A, Greenberg D, Winters T, Williams M, Vernon S, Collins VP. National Cancer Information Network Brain Tumour G: Glioblastoma in England: 2007-2011. Eur J Cancer. 2015;51(4):533-42.

9. Ostrom QT, Gittleman H, Fulop J, Liu M, Blanda R, Kromer C, Wolinsky Y, Kruchko C, Barnholtz-Sloan JS. CBTRUS Statistical Report: Primary brain and central nervous system tumors diagnosed in the United States in 20082012. Neuro-oncology. 2015;17(Suppl 4):iv1-iv62.

10. Brown TJ, Brennan MC, Li M, Church EW, Brandmeir NJ, Rakszawski KL, Patel AS, Rizk EB, Suki D, Sawaya R, et al. Association of the Extent of resection with survival in Glioblastoma: a systematic review and meta-analysis. JAMA Oncol. 2016;2(11):1460-9.

11. Almenawer SA, Badhiwala JH, Alhazzani W, Greenspoon J, Farrokhyar F, Yarascavitch B, Algird A, Kachur E, Cenic A, Sharieff W, et al. Biopsy versus partial versus gross total resection in older patients with high-grade glioma: a systematic review and meta-analysis. Neuro-oncology. 2015;17(6):868-81.

12. Hess KR. Extent of resection as a prognostic variable in the treatment of gliomas. J Neurooncol. 1999;42(3):227-31.

13. Sanai $N$, Berger MS. Glioma extent of resection and its impact on patient outcome. Neurosurgery. 2008;62(4):753-64 discussion 264-756.

14. Stupp R, Mason WP, van den Bent MJ, Weller M, Fisher B, Taphoorn MJ, Belanger K, Brandes AA, Marosi C, Bogdahn U, et al. Radiotherapy plus concomitant and adjuvant temozolomide for glioblastoma. N Engl J Med. 2005;352(10):987-96.

15. Weller M, van den Bent M, Tonn JC, Stupp R, Preusser M, Cohen-JonathanMoyal E, Henriksson R, Rhun EL, Balana C, Chinot O, et al. European Association for Neuro-Oncology (EANO) guideline on the diagnosis and treatment of adult astrocytic and oligodendroglial gliomas. Lancet Oncol. 2017;18(6):e315-29.

16. Stupp R, Brada M, van den Bent MJ, Tonn JC, Pentheroudakis G, Group EGW. High-grade glioma: ESMO Clinical Practice Guidelines for diagnosis, treatment and follow-up. Ann Oncol. 2014;25(Suppl 3):iii93-101.

17. Brown NF, Carter TJ, Ottaviani D, Mulholland P. Harnessing the immune system in glioblastoma. Br J Cancer. 2018;119(10):1171-81.

18. Fecci PE, Mitchell DA, Whitesides JF, Xie W, Friedman AH, Archer GE, Herndon JE, Bigner DD, Dranoff G, Sampson JH. Increased regulatory T-cell fraction amidst a diminished CD4 compartment explains cellular immune defects in patients with malignant Glioma. Cancer Res. 2006;66(6):3294.

19. Morford LA, Elliott LH, Carlson SL, Brooks WH, Roszman TL. T cell receptormediated signaling is defective in T cells obtained from patients with primary intracranial tumors. J Immunol. 1997;159(9):4415.

20. Choi BD, Fecci PE, Sampson JH. Regulatory T cells move in when Gliomas say "I DO". Clin Cancer Res. 2012;18(22):6086-8.

21. Roszman TL, Brooks WH. Immunobiology of primary intracranial tumours. III. Demonstration of a qualitative lymphocyte abnormality in patients with primary brain tumours. Clin Exp Immunol. 1980;39(2):395-402

22. Ooi YC, Tran P, Ung N, Thill K, Trang A, Fong BM, Nagasawa DT, Lim M, Yang I. The role of regulatory T-cells in glioma immunology. Clin Neurol Neurosurg. 2014;119(0):125-32

23. Krummel MF, Allison JP. CD28 and CTLA-4 have opposing effects on the response of T cells to stimulation. J Exp Med. 1995;182(2):459-65.

24. Linsley PS, Bradshaw J, Greene J, Peach R, Bennett KL, Mittler RS. Intracellular trafficking of CTLA-4 and focal localization towards sites of TCR engagement. Immunity. 1996;4(6):535-43.

25. Takahashi T, Tagami T, Yamazaki S, Uede T, Shimizu J, Sakaguchi N, Mak TW, Sakaguchi S. Immunologic self-tolerance maintained by CD25(+)CD4(+) regulatory $T$ cells constitutively expressing cytotoxic T lymphocyteassociated antigen 4. J Exp Med. 2000;192(2):303-10.

26. Leach DR, Krummel MF, Allison JP. Enhancement of antitumor immunity by CTLA-4 blockade. Science (New York, NY). 1996:271(5256):1734-6.

27. Postow MA, Callahan MK, Wolchok JD. Immune checkpoint blockade in Cancer therapy. J Clin Oncol. 2015;33(17):1974-82.

28. Brunet JF, Denizot F, Luciani MF, Roux-Dosseto M, Suzan M, Mattei MG, Golstein P. A new member of the immunoglobulin superfamily--CTLA-4. Nature. 1987;328(6127):267-70.

29. Fecci PE, Ochiai H, Mitchell DA, Grossi PM, Sweeney AE, Archer GE, Cummings T, Allison JP, Bigner DD, Sampson JH. Systemic CTLA-4 blockade ameliorates glioma-induced changes to the CD4+ T cell compartment without affecting regulatory T-cell function. Clin Cancer Res. 2007;13(7): 2158-67.

30. Reardon DA, Gokhale PC, Klein SR, Ligon KL, Rodig SJ, Ramkissoon SH, Jones KL, Conway AS, Liao X, Zhou J, et al. Glioblastoma eradication following immune checkpoint blockade in an Orthotopic, Immunocompetent model. Cancer Immunol Res. 2016;4(2):124-35.

31. Wainwright DA, Chang AL, Dey M, Balyasnikova IV, Kim CK, Tobias A, Cheng $Y$, Kim JW, Qiao J, Zhang L, et al. Durable therapeutic efficacy utilizing combinatorial blockade against IDO, CTLA-4, and PD-L1 in mice with brain tumors. Clin Cancer Res. 2014;20(20):5290-301.

32. Genoud V, Marinari E, Nikolaev SI, Castle JC, Bukur V, Dietrich PY, Okada H, Walker PR. Responsiveness to anti-PD-1 and anti-CTLA-4 immune checkpoint blockade in SB28 and GL261 mouse glioma models. Oncoimmunology. 2018;7(12):e1501137.

33. Margolin K, Ernstoff MS, Hamid O, Lawrence D, McDermott D, Puzanov I, Wolchok JD, Clark JI, Sznol M, Logan TF, et al. Ipilimumab in patients with melanoma and brain metastases: an open-label, phase 2 trial. Lancet Oncol. 2012;13(5):459-65.

34. Konstantinou MP, Dutriaux C, Gaudy-Marqueste C, Mortier L, Bedane C, Girard C, Thellier S, Jouary T, Grob JJ, Richard MA, et al. Ipilimumab in melanoma patients with brain metastasis: a retro-spective multicentre evaluation of thirty-eight patients. Acta Derm Venereol. 2014;94(1):45-9.

35. Queirolo P, Spagnolo F, Ascierto PA, Simeone E, Marchetti P, Scoppola A, Del Vecchio M, Di Guardo L, Maio M, Di Giacomo AM, et al. Efficacy and safety of ipilimumab in patients with advanced melanoma and brain metastases. J Neurooncol. 2014;118(1):109-16.

36. Common Terminology Criteria for Adverse Events Version 4.03 [https://evs. nci.nih.gov/ftp1/CTCAE/CTCAE_4.03/CTCAE_4.03_2010-06-14_ QuickReference_5x7.pdf]. Accessed 12 Nov 2019.

37. Mandel JJ, Yust-Katz S, Patel AJ, Cachia D, Liu D, Park M, Yuan Y, Kent TA, de Groot JF. Inability of positive phase II clinical trials of investigational treatments to subsequently predict positive phase III clinical trials in glioblastoma. Neuro-Oncology. 2018;20(1):113-22.

38. Shukla SA, Bachireddy P, Schilling B, Galonska C, Zhan Q, Bango C, Langer R, Lee PC, Gusenleitner D, Keskin DB, et al. Cancer-Germline Antigen Expression Discriminates Clinical Outcome to CTLA-4 Blockade. Cell. 2018; 173(3):624-33 e628

39. Havel JJ, Chowell D, Chan TA. The evolving landscape of biomarkers for checkpoint inhibitor immunotherapy. Nat Rev Cancer. 2019;19(3):133-50.

40. Chowell D, Morris LGT, Grigg CM, Weber JK, Samstein RM, Makarov V, Kuo F, Kendall SM, Requena D, Riaz N, et al. Patient HLA class I genotype influences cancer response to checkpoint blockade immunotherapy. Science. 2018;359(6375):582-7.

41. Davoli T, Uno H, Wooten EC, Elledge SJ. Tumor aneuploidy correlates with markers of immune evasion and with reduced response to immunotherapy. Science. 2017:355(6322):eaaf8399.

42. Valpione S, Pasquali S, Campana LG, Piccin L, Mocellin S, Pigozzo J, ChiarionSileni $V$. Sex and interleukin-6 are prognostic factors for autoimmune toxicity following treatment with anti-CTLA4 blockade. J Transl Med. 2018;16(1):94.

43. Chaput N, Lepage P, Coutzac C, Soularue E, Le Roux K, Monot C, Boselli L, Routier E, Cassard L, Collins M, et al. Baseline gut microbiota predicts clinical response and colitis in metastatic melanoma patients treated with ipilimumab. Ann Oncol. 2019.

44. Pinato DJ, Howlett S, Ottaviani D, et al. Association of Prior Antibiotic Treatment With Survival and Response to Immune Checkpoint Inhibitor Therapy in Patients With Cancer [published online ahead of print, 2019 Sep 12]. JAMA Oncol. 2019;e192785. https://doi.org/10.1001/jamaoncol.2019.2785.

\section{Publisher's Note}

Springer Nature remains neutral with regard to jurisdictional claims in published maps and institutional affiliations.

\section{Ready to submit your research? Choose BMC and benefit from:}

- fast, convenient online submission

- thorough peer review by experienced researchers in your field

- rapid publication on acceptance

- support for research data, including large and complex data types

- gold Open Access which fosters wider collaboration and increased citations

- maximum visibility for your research: over $100 \mathrm{M}$ website views per year

At $\mathrm{BMC}$, research is always in progress.

Learn more biomedcentral.com/submission 